\title{
A standardized cytological and immunochemical method for the analysis of fine-needle spleen aspirates: Assessment of leukocyte population changes in canine visceral leishmaniosis
}

\author{
Stella Maria Barrouin-Melo a,b,c,*, Daniela Farias Larangeira a , \\ Silvana Ornelas Santos ${ }^{c}$, Adenizar Delgado Chagas-Júnior ${ }^{c}$, \\ Mariza Paixão ${ }^{\mathrm{e}}$, Paulo Henrique Palis Aguiar ${ }^{\mathrm{a}, \mathrm{b}, \mathrm{c}}$, \\ Washington Luís Conrado dos-Santos ${ }^{\mathrm{a}, \mathrm{d}}$, \\ Lain Pontes-de-Carvalho ${ }^{\text {a,d }}$

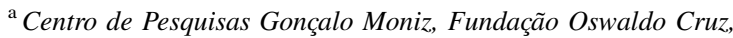 \\ Rua Valdemar Falcão 121, Salvador 40295-001, Brazil \\ ${ }^{\mathrm{b}}$ Departamento de Patologia e Clínicas, Escola de Medicina Veterinária, Universidade Federal da Bahia, \\ Av. Ademar de Barros 500, Salvador 40170-000, Brazil \\ ${ }^{\mathrm{c}}$ Laboratório de Infectologia Veterinária, Escola de Medicina Veterinária, Universidade Federal da Bahia, \\ Av. Ademar de Barros 500, Salvador 40170-000, Brazil \\ ${ }^{\mathrm{d}}$ Escola Bahiana de Medicina e Saúde Pública, Fundação para o Desenvolvimento das Ciências, Salvador, Brazil \\ ${ }^{\mathrm{e}}$ Laboratório Central do Estado da Bahia, Rua Valdemar Falcão 123, Salvador 40296-710, Brazil
}

Received 31 May 2005; received in revised form 13 January 2006; accepted 18 January 2006

\begin{abstract}
A method for the evaluation of splenic cellularity using samples collected by fine-needle aspirative biopsy was standardized in this work. The procedure includes erythrocyte lysing, preparation of cytospin films and staining by histochemical and immunocytochemical techniques. The cellular profiles of spleen preparations were compared with those observed in peripheral blood samples subjected to the same procedure. Two groups were compared, one consisting of 14 healthy uninfected and the other of 15 polysymptomatic Leishmania chagasi/infantum-infected dogs, from an endemic area for visceral leishmaniosis. Cell populations were identified by conventional hematoxilin-eosin and Wright' stainings, and by immunocytochemistry using monoclonal antibodies against canine CD45RA and CD45RB, phagocytes and a pan-leukocyte antigen. Larger neutrophil $(P<0.0001)$ and monocyte/macrophage $(P=0.0036)$ relative counts and lower lymphocyte relative counts $(P<0.0001)$ were found in the spleen, and not in the blood, of the animals with leishmaniosis than in those of the healthy animals. The proportions of $\mathrm{CD}_{45 \mathrm{RB}^{+}}$cells were higher, and of CD45RA ${ }^{+}$cells were lower, both in the spleen and in the blood of animals with
\end{abstract}

\footnotetext{
* Corresponding author. Tel.: +55 713176 2200x257; fax: +55 7131762204

E-mail address: barrouin@ufba.br (S.M. Barrouin-Melo).
} 
leishmaniosis than in those of healthy dogs $(P<0.05)$. Additionally, hematoxilin-eosin-stained cytospins of spleen aspirates from Leishmania-infected animals permitted the easy visualization of amastigote forms inside phagocytes, under light microscopy.

(C) 2006 Elsevier B.V. All rights reserved.

Keywords: Spleen; Canine; Fine-needle aspirative biopsy; Leukocyte populations; Canine visceral leishmaniosis

\section{Introduction}

Fine-needle spleen aspiration for direct microscopic examination or culture still represents the mainstream confirmative diagnostic test of canine visceral leishmaniosis (CVL) in most countries where the disease is endemic (Iniesta et al., 2002). Changes in lymphoid organs, associated to the intra-phagocyte proliferation of Leishmania chagasi or Leishmania infantum amastigote forms, are a remarkable element of the clinical and pathological characteristics of CVL (Natami et al., 2000; Tafuri et al., 2001). Indeed, variable degree of splenomegaly is found in almost every infected dog (Blavier et al., 2001; BarrouinMelo et al., 2006) and it is believed that the spleen plays a central role in the outcome of the infection (Kaye et al., 2004). However, although an association between the early immunological events taking place in the spleen and the development of leishmaniosis has been reported in a murine model (Melby et al., 2001), the same sort of phenomenon needs to be investigated in CVL. In CVL, a dog that develops a cellular immune response, associated to a predominance of IL12 and IFN- $\gamma$, may become asymptomatic or even cured (Abranches et al., 1991; Pinelli et al., 1994; Deplazes et al., 1995). On the other hand, the animal may develop a severe and progressive disease, associated with the presence of IL-10 and IL-4 and a predominantly humoral immune response (Pinelli et al., 1994), which is incapable of containing the spread of the infection in the host organism (Ferrer et al., 1995; Moreno et al., 1999). In this situation, a wasting disease takes place with a large number of non-specific clinical signs, such as cutaneous, periocular and ocular lesions; nephropathy; skeletal muscle, cardiovascular, digestive and respiratory dysfunctions; lymphoid organ hypertrophy; and haematic disorders (Barrouin-Melo et al., 2006; Ferrer et al., 1995; Blavier et al., 2001).
Besides being a reservoir of Leishmania parasites in endemic areas (Molina et al., 1999; Guarga et al., 2000), and having great importance as companion animals, dogs are also used in experimental models of human diseases (Faldyna et al., 2005), specially in the study of parasite-host interactions, immune responses, and in the development of new vaccines and therapeutic agents (Williams, 1997; Reis et al., 2005).

Cytologic investigations provide important information on splenic changes, mostly in neoplasic or inflammatory illnesses, in both human (Zeppa et al., 2003) or veterinary (Christopher, 2003) medicines. The use of the recently available monoclonal antibodies specific for canine lymphoid cell subpopulations may greatly add to the analytical power of these investigations in the dog (Cobbold and Metcalfe, 1994; Faldyna et al., 2005). The fine-needle aspirative biopsy of the spleen is a good source of material for those analyses, serving as an alternative to splenectomy or even to the sacrifice of animals for obtaining tissue samples, particularly in experimental conditions.

In the study described below, splenocytes from healthy dogs, and from animals with visceral leishmaniosis (VL), were evaluated by means of chemical and immunochemical techniques, in order to provide: (a) the standardization of a practical and simple evaluation tool for splenic alterations and (b) information on splenic cell alterations in the active form of the disease. Monoclonal antibodies against a canine CD45 homologue, canine phagocytes, canine CD45RA and canine CD45RB antigens were used. Naïve $T$ cells, helper $T$ cells secreting IFN- $\gamma$ and a wide range of $\mathrm{B}$ cells express the high molecular weight (220-240 kDa) CD45RA antigen (Cobbold and Metcalfe, 1994; Zuckermann et al., 1998), while the CD45RB antigen has been associated to $\mathrm{CD} 4^{+} \mathrm{T}$ cells that had been activated in the course of a viral (Varga and Welsh, 1996) or protozoan (Gomes-Pereira et al., 2004) infection. Fine-needle aspirations, as 
performed in the work described below, can allow repeated (Barrouin-Melo et al., 2006) evaluations of splenic changes in dogs, contrasting with the surgical or necropsy procedures used in most reports on the pathological alterations of CVL. To these authors' best knowledge, a standardized method for the analytical approach of canine spleen samples, and its application to the study of CVL, as described in this report, have not been reported elsewhere.

\section{Material and methods}

\subsection{Animals and experimental design}

The standardization of morphological and immunochemical identifications of leukocyte populations in spleen aspirates was carried out in material collected from six healthy mixed bred young adult dogs (three males and three females). They were maintained in a kennel at the Gonçalo Moniz Research Center, Oswaldo Cruz Foundation (http://www.cpqgm.fiocruz.br/), in a non-endemic area for VL, where they underwent routine medical examinations, and regularly received multivalent and rabies vaccines, and deworming medication.
A comparative study of sick Leishmania-infected and healthy non-infected animals was made in material collected from 15 dogs with VL, and from 14 healthy dogs, all of them from an endemic area for VL (cities located at the North-East of Bahia State, Brazil). The polysymptomatic animals had been tested positive for anti-Leishmania antibodies in serological tests, and their diagnoses were confirmed by the observation of amastigotes in spleen aspirate cultures. This group of animals included mongrel and purebred dogs, of both sexes, having different body sizes, and ages varying from 10 months to 8 years old (Table 1). All of them were domiciled. They were considered polysymptomatic when at least three of the following signs were present: mucous membrane colour changes (paleness, icterus or congestion); mucous membrane nodular or ulcerative lesions, particularly on the lips and nose; cutaneous changes (alopecia, depigmentation, exfoliation, nodules, ulceration and/or pustule formation); abnormal growth of the claws; ocular disturbances (conjunctivitis, keratitis, keratoconjunctivitis sicca, blepharitis and/or uveitis); weight loss; enlargement of lymph nodes and spleen; bleeding events (epistaxis; and gingival or abnormal genital bleedings); prostration or apathy. Fourteen control

Table 1

General, parasitological and serological profile of polysymptomatic animals from an area endemic for visceral leishmaniosis

\begin{tabular}{|c|c|c|c|c|c|c|c|}
\hline \multirow[t]{2}{*}{ Animal } & \multirow[t]{2}{*}{ Age (year) } & \multirow[t]{2}{*}{ Gender } & \multirow[t]{2}{*}{ Breed } & \multirow[t]{2}{*}{ Parasite load ${ }^{\mathrm{a}}$} & \multicolumn{3}{|c|}{ Anti-Leishmania antibody activity (OD) } \\
\hline & & & & & $\operatorname{IgG} 1^{\mathrm{b}}$ & $\operatorname{IgG} 2^{\mathrm{c}}$ & Total $\mathrm{IgG}^{\mathrm{d}}$ \\
\hline$\# 1$ & 1 & M & Dobermann & 31 & 0.15 & 1.98 & 1.72 \\
\hline$\# 2$ & 6 & M & Beagle & 4 & 0.63 & 2.05 & 1.85 \\
\hline$\# 3$ & 0.8 & M & Brazilian Fila & 3 & 0.49 & 2.27 & 2.10 \\
\hline$\# 4$ & 4 & $\mathrm{~F}$ & Mongrel & 47 & 0.94 & 1.78 & 2.40 \\
\hline$\# 5$ & 3 & $\mathrm{~F}$ & Mongrel & 26 & NT & NT & NT \\
\hline \#6 & 1 & $\mathrm{~F}$ & Mongrel & 2 & 0.61 & 1.68 & 1.82 \\
\hline$\# 7$ & 2 & M & Brazilian Fila & 14 & 0.18 & 1.53 & 1.48 \\
\hline$\# 8$ & 1 & $\mathrm{~F}$ & Poodle & 9 & 1.47 & 1.68 & 1.86 \\
\hline$\# 9$ & 2 & M & Beagle & 2 & 0.26 & 1.93 & 2.01 \\
\hline$\# 10$ & 3 & $\mathrm{~F}$ & Mongrel & 3 & 0.23 & 1.77 & 2.02 \\
\hline$\# 11$ & 1 & $\mathrm{~F}$ & Rottweiler & 4 & 0.35 & 2.46 & 1.94 \\
\hline$\# 12$ & 5 & $\mathrm{~F}$ & Mongrel & - & 0.18 & 1.77 & 1.99 \\
\hline$\# 13$ & 5 & M & Rottweiler & 1 & 0.58 & 1.79 & 1.97 \\
\hline$\# 14$ & 8 & M & German Shepperd & 6 & 0.20 & 1.93 & 1.86 \\
\hline \#15 & 1 & M & Pitbull & 1 & $\mathrm{NT}^{\mathrm{e}}$ & NT & NT \\
\hline
\end{tabular}

\footnotetext{
${ }^{a}$ Number of parasitized cells per 500 mononuclear cells in HE-stained cytospin spleen aspirates, under optical microscopy.

${ }^{\mathrm{b}}$ Individual median values for $\mathrm{IgG} 1$; positive control $\mathrm{OD}=0.498$ and negative control $\mathrm{OD}=0.066$.

${ }^{\mathrm{c}}$ Individual median values for $\mathrm{IgG} 2$; positive control $\mathrm{OD}=1.990$ and negative control $\mathrm{OD}=0.110$.

${ }^{\mathrm{d}}$ Individual median values for total $\mathrm{IgG}$; positive control $\mathrm{OD}=2.200$ and negative control $\mathrm{OD}=0.117$; cut-off $=0.392$.

e NT: non-tested.
} 
dogs were from a breeding kennel, maintained under sanitary and nutritional control by veterinary supervision, which included regular testing for canine common infectious diseases. All of them were adults, with ages varying from 2 to 6 years old, of both sexes, clinically healthy and negative in serological and parasitological tests for VL.

\subsection{Ethics}

All procedures carried out on the animals were in accordance with guidelines defined by the Committee of Ethics in Animal Experimentation of the Oswaldo Cruz Foundation, Brazil.

\subsection{Spleen and blood sample collection}

The procedure for spleen aspiration was performed in accordance with a previously reported technique (Barrouin-Melo et al., 2006). Briefly, following tranquilization with an intravenous injection of $0.5 \mathrm{mg} / \mathrm{kg}$ of acepromazine, the dogs were restrained in right lateral recumbency, the hair was removed and asepsis achieved by rubbing a $2 \%$ iodine-alcohol solution over the skin. The spleen was localized by palpation and the aspiration made with $18 \mathrm{G} \times 38 \mathrm{~mm}$ or $21 \mathrm{G} \times 32 \mathrm{~mm}$ needles, depending on the dogs size, connected to a $10 \mathrm{~mL}$ sterile syringe. The access to the organ was determined by the paracostal approach, and the needle introduced in the left flank, $1-3 \mathrm{~cm}$ from the ventral extremity of the last rib. After perforating the spleen, the gentlest negative pressure that allowed the passage of a blood-like, thick material into the syringe was made by pulling the syringe's piston. The whole aspiration procedure usually took a few seconds, and yielded samples of approximately $100-400 \mu \mathrm{L}$. The material was carefully flushed into a sterile tube containing $10 \mathrm{~mL}$ of RPMI 1640 medium (Sigma Chemical Co., St Louis, USA) with $50 \mathrm{UI} / \mathrm{mL}$ of heparin and kept on ice, until being processed in the laboratory, for leukocyte purification. The remaining spleen material in the syringe was kept inside it to be seeded into culture medium, for parasitological diagnosis.

Ten-millilitre volumes of peripheral blood were collected from the antebrachial cephalic vein. Of these, $2 \mathrm{~mL}$ were carefully mixed with $10 \mathrm{~mL}$ of $\mathrm{RPMI} /$ heparin medium and kept on ice until its processing for leukocyte purification. The remaining amount of blood was drawn into a blood clotting tube for the preparation of serum.

\subsection{Serological and parasitological diagnosis of visceral leishmaniosis}

\subsubsection{ELISA for $I g G, I g G 1$ and $I g G 2$}

The presence of anti-Leishmania antibodies in the sera of all studied dogs was investigated by a classical indirect ELISA, using soluble $L$. chagasi antigens (SLA), as described by Paranhos-Silva et al. (1996), with few modifications. Pools of positive or negative canine sera for anti-Leishmania antibodies were used as controls. The SLA consisted of the soluble fraction (the supernatant of a $10,000 \times g, 30$ min centrifugation) of lysed promastigotes from a local Leishmania strain, isolated from a sick dog, and characterized as $L$. chagasi by means of isoenzyme electrophoresis and comparison with a reference strain (LTCC - Leishmania Typing Culture Collection - WDCM731). Briefly, 96-well plates (Corning-Costar Corp., New York, USA) were coated with the antigen overnight at $4{ }^{\circ} \mathrm{C}$ (incubation with $100 \mu \mathrm{L}$ per well of $5 \mu \mathrm{g}$ of protein per $\mathrm{mL}$ of $0.1 \mathrm{M}$ carbonate-bicarbonate solution, $\mathrm{pH}$ 9.6). Non-specific antibody binding was blocked with $5 \%$ skimmed milk (w/v) in $0.15 \mathrm{M}$ phosphate-buffered saline solution, $\mathrm{pH} 7.4$ (PBS), containing $0.05 \%$ Tween 20 (PBS-T), for $1 \mathrm{~h}$, at $37{ }^{\circ} \mathrm{C}$. Control and test serum samples were added at 1:400 dilution in $1 \%$ skimmed milk in PBS-T, $100 \mu \mathrm{L} /$ well, and incubated for $1 \mathrm{~h}$ at $37^{\circ} \mathrm{C}$. A peroxidase-conjugated rabbit anti-dog IgG (Sigma Chemical Co.) was added at the dilution of 1:5000 in $1 \%$ skimmed milk in PBS-T, $100 \mu \mathrm{L} /$ well and incubated for $1 \mathrm{~h}$ at $37^{\circ} \mathrm{C}$. The enzymatic reaction was developed with $o$-phenilenediamine (Sigma Chemical Co.) and stopped after $15 \mathrm{~min}$ with $25 \mu \mathrm{L} /$ well of $4 \mathrm{~N}_{2} \mathrm{SO}_{4}$. Absorbance values were read at $490 \mathrm{~nm}$. The cut-off value for IgG antibodies was determined by the receiver operating characteristics (ROC) curve, using corrected absorbance values obtained with sera from $30 \mathrm{~L}$. chagasi-infected dogs, positive in serological and parasitological tests, and from 71 healthy dogs, living in non-endemic areas. All determinations were carried out in triplicate and the mean values above the cut-off for $\mathrm{IgG}$ were considered to be positive results. 
For determination of $\operatorname{IgG} 1$ and $\operatorname{IgG} 2$ antibody activities against Leishmania antigens, the sera of the infected animals were tested in an indirect ELISA, utilizing peroxidase-conjugated goat anti-dog IgG1 or sheep anti-dog IgG2 (Bethyl, Montgomery, USA), at dilutions of 1:600 and 1:2500, respectively, in the protocol described above.

\subsubsection{Culture and microscopy for parasite detection}

Samples of spleen aspirates were cultured in a biphasic medium containing $1.5 \mathrm{~mL}$ of blood-agar (solid medium) and $2 \mathrm{~mL}$ of Schneider's (liquid) medium (Sigma Chemical Co.) supplemented with $20 \%$ of fetal bovine serum (Gibco BRL, Grand Island, USA). Cultures were maintained at $23^{\circ} \mathrm{C}$ and examined weekly under light microscopy for 1 month for the presence of live, active promastigote forms. The direct microscopic examination of cytospin preparations of spleen cells was also performed, in order to evaluate the usefulness of the processed slides for parasitological diagnosis and for the possible assessment of parasite load in the spleen. The number of parasitized cells was counted per 500 mononuclear cells under light microscopy in cytospin preparations stained by hematoxilin and eosin (H-E).

\subsection{Preparation of cell suspensions and cytospins}

Spleen or blood samples, previously diluted 1:6 in RPMI/heparin solution, were further diluted 1:4 in PBS containing EDTA to a final concentration of $1 \mathrm{mg} / \mathrm{mL}$, and centrifuged for $10 \mathrm{~min}$ at $450 \times g$ at room temperature (RT). The supernatant was discarded and the erythrocytes were lysed by incubation with a $10 \%$ (w/v) ammonium chloride solution in $\mathrm{H}_{2} \mathrm{O}$ for $10 \mathrm{~min}$. After centrifugation, the cells were washed twice with Hank's buffered salt solution (HBSS, Sigma Chemical Co.) for $10 \mathrm{~min}$ at $450 \times g$, at RT. The cells were resuspended in HBSS to a concentration of $10^{7}$ cells $/ \mathrm{mL}$ before the cytocentrifugation. Three different procedures were compared in terms of their capacity to confer adherence to glass and to preserve morphological aspects of the leukocytes. In one procedure, cell suspensions were mixed with an equal volume of Shandon cell collection fluid (Thermo Shandon, Pittsburgh, USA) and cytocentrifuged $(100 \mu \mathrm{L} /$ well at $350 \times g$ during $10 \mathrm{~min}$; Revan
Scientific Instruments, São Paulo, Brazil). In the other two procedures, the cells were not diluted with Shandon cell collection, fluid but were cytocentrifuged onto poly-L-lysine- or Silane (Sigma Chemical Co.)-covered slides. The slides were air-dried at RT, fixed with $100 \%$ acetone at $4{ }^{\circ} \mathrm{C}$ for $5 \mathrm{~min}$ and stored at $-70{ }^{\circ} \mathrm{C}$, in plastic boxes, until being utilized in the assays.

\subsection{Staining assays and leukocyte populations' count}

Cytospin preparations were stained with Wright's and hematoxilin-eosin (H-E) techniques and examined by conventional microscopy for differential leukocyte counting, parasite identification, assessment of the rate of macrophage infection and estimation of parasite burden. A total of 500 cells were counted with $40 \times$ objective lens, and the amount of parasitized cells was expressed as percentage of the whole leukocyte population.

\subsection{Immunostaining assays}

\subsubsection{Monoclonal and polyclonal antibodies}

Rat anti-canine CD45RA (YKIX 753.22 clone; Cobbold and Metcalfe, 1994) and anti-canine CD45RB (YKIX 716.13 clone; Cobbold and Metcalfe, 1994) monoclonal antibodies (mAbs) were a kind gift from Dr. S. Cobbold. A mouse IgG2a anticanine pan-leukocyte marker, the AB6 mAb, which has a reactivity pattern, both in terms of cell and tissue epitope localization, and of the molecular weights of the recognized proteins, compatible with that of an anti-CD45 antibody (Aguiar et al., 2004a), and a mouse IgG1 anti-canine monocyte/macrophage and polymorphonuclear cell antigen, the IH1 mAb (Aguiar et al., 2004b), were developed and tested in our laboratory. All mAbs were used unlabeled. IgG from normal rat or mouse sera was used as isotype controls. Biotinylated rabbit anti-mouse or rat IgG (Vector Lab. Inc., Burlingame, USA) were used as secondary antibodies. FITC-labeled streptavidin (Sigma Chemical Co.) was utilized for immunofluorescence assays and peroxidase-conjugated stravidin (Sigma Chemical Co.) for immunoperoxidase assays. The optimal dilutions of each $\mathrm{mAb}$, and of the secondary antibodies and streptavidin conjugates, were 
previously determined by testing them, serially diluted, in the immunocytoassays.

\subsubsection{Immunofluorescence and immunoperoxidase assays}

The immunofluorescence technique was utilized for testing the reactivity of the monoclonal antibodies with the canine spleen cells, and the immunoperoxidase assay for the differential countings. Blood and spleen cytospin preparations were rehydrated with PBS, during $1 \mathrm{~min}$, at RT. For the immunofluorescence, non-specific binding was blocked by incubation with PBS containing $10 \%$ of normal rabbit serum and $1 \%$ of fetal calf serum (Gibco BRL), for $30 \mathrm{~min}$, at $\mathrm{RT}$, in a moist chamber. Cells were washed twice in PBS-T bath for $1 \mathrm{~min}$. The monoclonal antibodies were added at a dilution of 1:10 (anti-CD45RA, antiCD45RB) or 1:40 (AB6 and IH1) in PBS, and incubated for $1 \mathrm{~h}$, in a moist chamber, at RT. After two washing steps, biotinylated secondary anti-mouse $(1: 100)$ or anti-rat $(1: 200)$ antibodies were overlaid and incubated for $1 \mathrm{~h}$ in a moist chamber, at RT. Following two washing steps, FITC-labeled streptavidin was added and incubated for $30 \mathrm{~min}$, in a dark room. The slides were washed twice with PBS-T, and $50 \mu \mathrm{g} / \mathrm{mL}$ of propidium iodide in PBS was incubated for 1 min to stain the cell nucleus. After two more washings with PBS-T, followed by distilled water washings, the slides were covered with an anti-fading solution, consisting of $10 \mathrm{mg} / \mathrm{mL} p$-phenylenediamine (Sigma Chemical Co.), in a $90 \%$ glycerol/PBS solution (v/v), mounted with coverslips and examined using fluorescent light microscopy.

For the immunoperoxidase technique, after the rehydration step, the cytospin preparations were overlaid with an endogenous peroxidase-blocking solution, consisting of $0.015 \% \mathrm{NaN}_{3}$ and $3 \% 30$ volume $\mathrm{H}_{2} \mathrm{O}_{2}$ in PBS, and incubated for $15 \mathrm{~min}$. PBS$\mathrm{T}$ washings were carried out and blocking of nonspecific binding was performed by incubation with $10 \%$ normal rabbit serum. Cells were washed twice with PBS-T and the anti-CD45RA (1:20), antiCD45RB (1:20), AB6 (1:100) or IH1 (1:40) mAbs, diluted in PBS, or the isotope controls, were added and incubated for $1 \mathrm{~h}$, in a moist chamber, at RT. After two washing steps, secondary biotinylated anti-mouse (1:100) or anti-rat (1:200) antibodies were overlaid and incubated for $1 \mathrm{~h}$ in a moist chamber, at RT.
Following two washing steps, peroxidase-conjugated streptavidin was added and incubated for $1 \mathrm{~h}$, in a moist chamber, at RT. The slides were washed twice with PBS-T and a substrate solution, consisting of $1 \%$ diaminobenzidine (Sigma Chemical Co.) and 2\% $\mathrm{H}_{2} \mathrm{O}_{2}$ in PBS, was applied for 1-3 min. After two more PBS-T and two distilled water washings, the cells were counterstained with hematoxilin and examined by light microscopy. For determining leukocyte subpopulations, 500 cells were counted with a $40 \times$ objective lens, and the proportion of stained cells was expressed as a percentage of the whole leukocyte population.

\subsection{Statistical analysis}

The differences between groups were evaluated using the unpaired Student's $t$-test. The $F$-test was applied to compare variances. $P$ values under 0.05 were considered to be statistically significant. The calculations were performed with Prism ${ }^{\circledR}$ software (GraphPad Software Inc.).

\section{Results}

\subsection{Fine-needle aspiration provides material for good-quality cytospin preparations of spleen}

All dogs tolerated well the spleen aspirations and no complications were observed or reported during or after the procedures. The volume of the obtained spleen samples varied from 100 to $400 \mu \mathrm{L}$. Cell yields varied from $2 \times 10^{7}$ to $8 \times 10^{7}$ viable spleen or peripheral blood leukocytes. The use of Silane, poly-Llysine or Shandon cytospin fluid led to similar numbers of cells retained in the cytospin preparations (not shown). The Shandon fluid, however, was superior in terms of preservation of cell morphology (Fig. 1). Both the H-E and Wright' staining methods allowed the differential counting of leukocyte populations. Spleen samples kept small sparse fragments of stromal tissue in the midst of the single cell suspensions, mostly composed by lymphocytes of various sizes (Fig. 1b). These fragments were characterized by groups of mononuclear cells, most with macrophage morphology. The cytospin preparations were appropriate for the visualization of Leishmania amastigotes (Fig. 1b) and for immuno- 

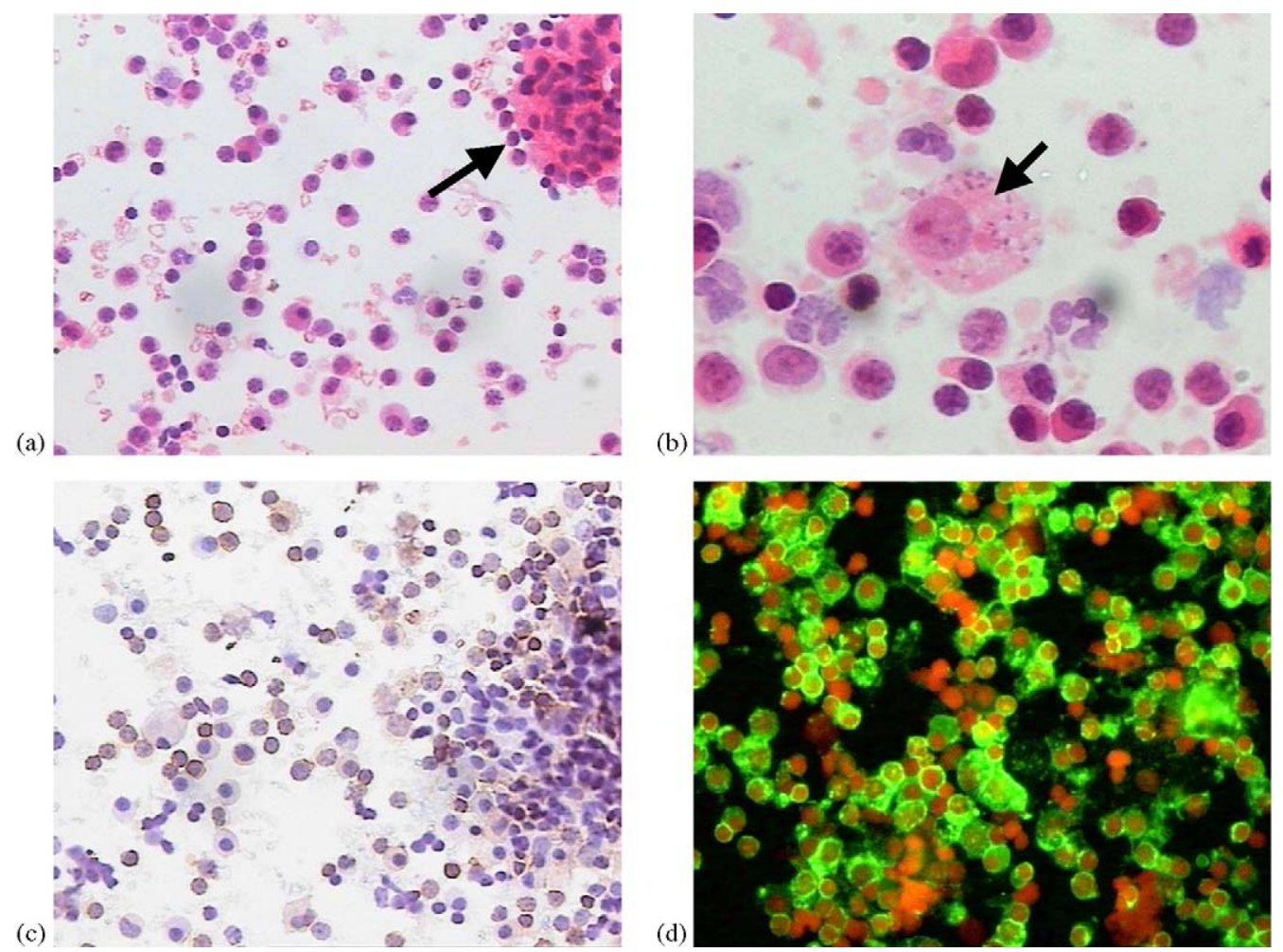

Fig. 1. Morphology (a and b) and staining with the AB6 monoclonal antibody, by immunoperoxidase (c) and indirect immunofluorescence (d), of cells in spleen aspirate cytospin preparations. A fragment of stromal tissue can be seen in (a), and a large macrophage, containing amastigote forms of Leishmania, in (b) (arrows). H-E staining in (a) and (b); magnification of 40 in (a), (c) and (d); magnification of 100 in (b).

cytochemistry by immunoperoxidase (Fig. 1c) and immunofluorescence (Fig. 1d) techniques.

\subsection{Parasitological and serological profile of dogs with clinical signs of visceral leishmaniosis}

No Leishmania parasites were isolated from animals in the healthy group and their serum IgG antiLeishmania antibody activities were always under the cut-off value. All symptomatic dogs were positive for $L$. chagasi in the culture of spleen aspirates (not shown) and in 13 of them in which IgG anti-Leishmania (mean $\mathrm{OD}=1.877 \pm 0.164$ ) antibody was tested for, its level was above the cut off value (Table 1). Parasite-specific $\mathrm{IgG} 1$ (mean $\mathrm{OD}=0.479 \pm 0.367$ ) and $\mathrm{IgG} 2$ (mean $\mathrm{OD}=1.862 \pm 0.248)$ antibodies were also detected in their sera (Table 1). There was a greater variability in the levels of IgG1 antibodies, which produced lower optical densities in the ELISA, than in those of IgG2 (Table 1).
The proportion of parasitized cells in relation to all splenocytes could be easily determined in the H\&Estained cytospin preparations. Variable proportions of parasitized cells were seen in spleen aspirates from different dogs (Table 1).

\subsection{Differences between the proportions of leukocytes in the spleen and blood of healthy dogs}

The spleen aspirates of healthy dogs from areas with and without leishmaniosis had a higher proportion of lymphocytes $(P<0.0001$ and $P=0.0064$, respectively) and a lower proportion of neutrophils $(P<0.0001$ and $P=0.012$, respectively) than blood samples (not shown). The ratios between mean percentages of neutrophils and mean percentages of lymphocytes were 0.27 in spleen aspirates and 3.2 in peripheral blood samples in healthy dogs from areas without leishmaniosis, and 0.4 in the spleen and 3.5 in 
the blood of healthy dogs from the area with leishmaniosis (not shown). There was no statistically significant difference between blood and spleen in terms of monocytes/macrophages or eosinophils proportions in both groups of dogs (not shown). The presence of mast cells or basophils was sporadic in samples from both origins (not shown). No statistical significant differences were found between the groups of healthy dogs from areas with and without leishmaniosis.

\subsection{Leishmania-infected polysymptomatic dogs undergo changes in spleen leukocyte populations}

The group of symptomatic animals also showed a higher proportion of lymphocytes $(P=0.0007)$ and a lower proportion of neutrophils $(P=0.0003)$ in spleen aspirates than in the peripheral blood (not shown). These animals had a significantly higher proportion of mononuclear phagocytes in the spleen than in the peripheral blood $(P=0.0084)$. In addition, they had a
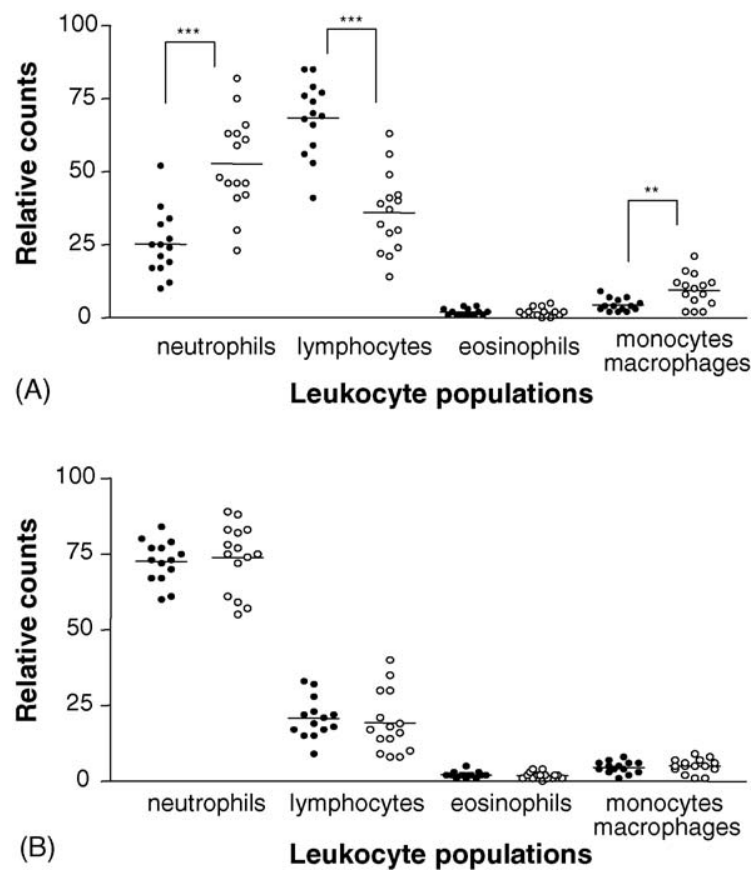

Fig. 2. Relative counts of canine leukocyte populations in spleen aspirate (A) and blood (B) cytospin preparations, stained by Wright's technique. Samples were obtained from 14 healthy noninfected dogs (O) and from 15 polysymptomatic Leishmaniainfected $\operatorname{dogs}(\bigcirc)$, all of them from an endemic area of visceral leishmaniosis. Statistical significance, $t$-test: ${ }^{* *} P<0.001$ ${ }^{* * * *} P<0.0001$. higher proportion of neutrophils $(P<0.0001)$ and macrophages $(P=0.0036)$ and a lower proportion of lymphocytes $(P<0.0001)$ in the spleen than the healthy controls from the endemic area (Fig. 2A). The splenic neutrophils/lymphocytes ratio was of 0.4 in the healthy animals, whereas in the symptomatic dogs' group it was of 1.5 . No statistically significant differences were found among leukocyte proportions in blood samples of sick and healthy dogs (Fig. 2B).

\subsection{Comparison of proportions of cells expressing different surface markers in symptomatic Leishmania-infected dogs and healthy dogs}

The spleen of Leishmania-infected dogs had higher relative numbers of $\mathrm{AB}^{+} \quad(P<0.0001), \quad \mathrm{IH}^{+}$ $(P<0.0001)$ and $\mathrm{CD}_{45 \mathrm{RB}^{+}}$cells $(P=0.0004)$, and lower counts of $\mathrm{CD}^{2} 5 \mathrm{RA}^{+}$cells $(P<0.0001)$ (Fig. 3A) than the spleen of healthy dogs. The same
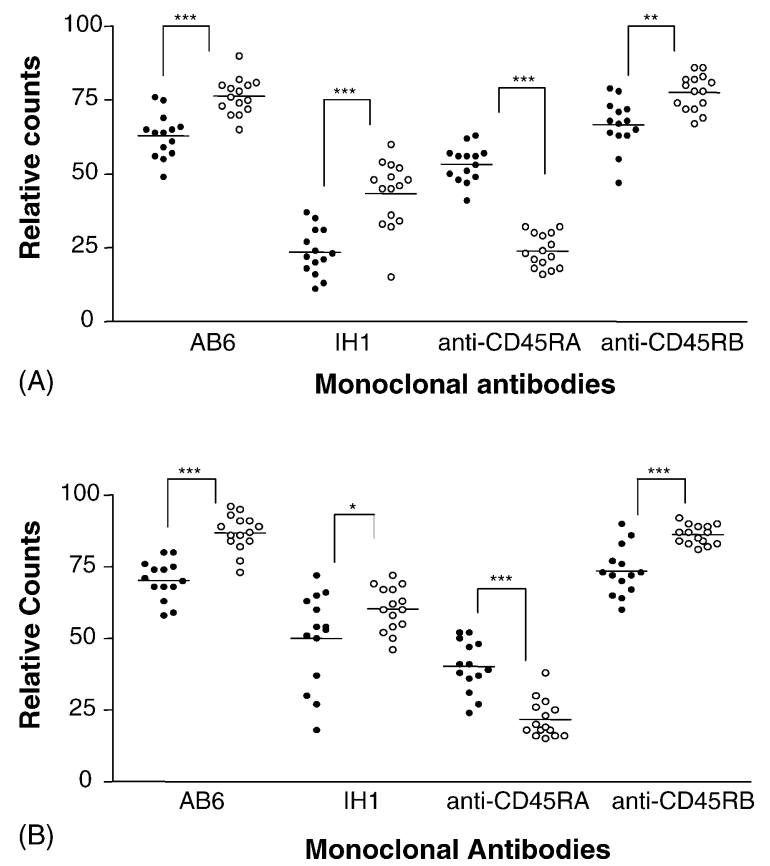

Fig. 3. Proportions of spleen (A) and blood (B) cells, stained with AB6 (anti-CD45), IH1 (anti-phagocyte), YKIX-753 (anti-CD45RA) and YKIX-716 (anti-CD45RB) monoclonal antibodies, by immunoperoxidase, in cytospin preparations from healthy $(\mathbf{O})$ and polysymptomatic Leishmania-infected dogs $(\bigcirc)$. All animals were from an endemic area for visceral leishmaniosis. Statistical significance, $t$-test: ${ }^{*} P<0.05 ;{ }^{* *} P<0.001 ;{ }^{* * *} P<0.0001$. 
pattern of differences between Leishmania-infected and healthy animals was found for blood cells $(P<0.05$; Fig. 3B).

\section{Discussion}

This work is part of a series of studies on the potential use of fine-needle spleen aspiration in the $\mathrm{dog}$, as a source of material for etiological and pathophysiological studies, focused in VL. Previous reports have documented the better sensitivity achieved with spleen samples for the parasitological diagnosis of $\mathrm{CVL}$, in comparison to lymph node samples (Barrouin-Melo et al., 2004), and demonstrated the safety of fine-needle spleen aspiration in dogs with VL (Barrouin-Melo et al., 2006). In the present study, its applicability to cytological and immunochemical studies is demonstrated.

Some authors have drawn attention to the limited amount of material usually obtained by fine-needle spleen aspiration in human beings (Zeppa et al., 2003), and the loss of cells during the immunochemical processing of canine specimens (Tipold et al., 1998). In order to minimize such problems, in the present work different products and protocols for cytospin preparation were compared, showing that a better cell morphology was attained by using the Shandon reagent. Approximately $250 \mu \mathrm{L}$ of spleen aspirates yielded about $10^{7}$ purified leukocytes, which allowed the production of about 20 cytospin spots, containing $5 \times 10^{5}$ cells each. Using commercially available monoclonal antibodies (anti-CD45RA and antiCD45RB) and antibodies developed in our laboratory (AB6 and IH1), these cytospins were shown to provide appropriate cells for immunochemical studies, and could therefore be analyzed by antibodies against other leukocyte markers. The finding of consistent differences between blood and spleen samples in terms of their phagocyte/lymphocyte proportions indicates that all aspirates were indeed from the splenic stroma, and not, accidentally, from local blood vessels. Moreover, the concentration of leukocytes, due to lysis of erythrocytes followed by cytospinning, and their staining by $\mathrm{H}-\mathrm{E}$, permitted an easier visualization of amastigote forms inside phagocytes than in spleen aspirate smears (Barrouin-Melo, unpublished observation). The procedure can indeed allow the determination of the proportions of parasites (Barrouin-Melo, unpublished observation) and of parasitized cells (Table 1) in the cytospins. This could possibly allow an estimation of parasite loads in groups of infected animals.

All 13 Leishmania-infected dogs that were tested for circulating anti-Leishmania antibodies had detectable total IgG and IgG2 antibodies, and most of them also had clearly detectable IgG1 antibodies. The presence of anti-Leishmania antibodies of both IgG subclasses may be a marker of active CVL, since the concomitance of antibodies of these two subclasses have been associated to progressive disease (Deplazes et al., 1995; Nieto et al., 1999; Quinnell et al., 2003).

Leishmania-infected and healthy animals differed in terms of leukocyte profiles in the spleen, as stained by Wright's technique, but not in the blood. Higher proportions of neutrophils, and particularly of macrophages, were found in the spleen of dogs with VL than in the spleen of healthy dogs. This was confirmed by the finding of increased proportions of IH1-stained cells in the infected dog samples. These results are in accordance with the findings of a macrophage hyperplasia (Kontos and Koutinas, 1993; Natami et al., 2000; Tafuri et al., 2001) and high numbers of $\mathrm{CD} 11 \mathrm{c}^{+}$and monocyte/macrophage cells (Sanchez et al., 2004) in the spleen of Leishmaniainfected dogs. These spleen cellularity changes may be due to an increased production of cytokines of the TNF family, as reported for murine and human visceral leishmaniosis (Engwerda et al., 2002; Kaye et al., 2004), and/or to an enhancement of the organspecific hematopoiesis, mediated by the colonystimulating factors GM-CSF, M-CSF and G-CSF, as described in a murine model of VL (Cotterell et al., 2000).

An increase in numbers of splenic phagocytes by itself could account for the relative decrease in proportions of lymphocytes in animals with VL. This reduction in lymphocyte proportions, however, was not homogeneous in the whole lymphocytic population: variations in the relative proportions of $\mathrm{CD}_{45 \mathrm{RA}^{+}}$and $\mathrm{CD} 45 \mathrm{RB}^{+}$cells were observed. The increased proportions of $\mathrm{CD}_{4} \mathrm{RB}^{+}$and $\mathrm{CD} 45^{+}$ (identified by the $\mathrm{AB} 6 \mathrm{mAb}$ ) and the reduced proportions of $\mathrm{CD}^{2} 5 \mathrm{RA}^{+} \mathrm{T}$ cells in Leishmaniainfected dogs, in relation to healthy controls, could reflect an activation of $\mathrm{T}$ cells (Tipold et al., 1998) 
during the infection. Although animals with VL differed from control animals, in terms of neutrophil, lymphocyte and macrophage/monocyte proportions, in the spleen but not in the blood (Fig. 2), both spleen and blood samples from these two groups of animals differed in the case of $\mathrm{CD} 45^{+}$cell proportions (Fig. 3). Whether these changes in $\mathrm{CD} 45^{+}$cell proportions occur simultaneously or sequentially in different tissues, and how they may affect the development of CVL, should be the aim of further studies.

The data reported herein are the first to describe and quantify leukocyte populations and subpopulations in dogs, using spleen aspirates from healthy and Leishmania-infected symptomatic dogs. The increases in macrophage and granulocyte proportions, associated with a low proportion of lymphocytes, mainly CD45RA ${ }^{+}$, and an increased proportion of CD45RB ${ }^{+}$ cells, in the spleen of dogs with VL, could be valuable parameters for the monitoring of CVL development. The easiness in disclosing this pattern of splenic changes without killing the animals, together with the possibility of estimating the spleen parasite burden in groups of Leishmania-infected dogs, could make the techniques described in this report useful for monitoring the possible effect of vaccine and/or immunotherapy candidates, as well as for clinical prognoses. Studies aiming at investigating the technique's reproducibility and whether repeated aspirations could, by themselves, significantly alter the cellular composition of the spleen aspirates should be carried out before the method could be used for the sequential monitoring of splenocyte alterations in infectious, lymphoproliferative and/or immunemediated canine diseases.

\section{Acknowledgement}

This work was supported by the Brazilian National Council for Research and Technological Development $(\mathrm{CNPq})$.

\section{References}

Abranches, P., Santos-Gomes, G., Rachamin, N., Campino, L., Schnur, L.F., Jaffe, C.L., 1991. An experimental model for canine visceral leishmaniasis. Parasite Immunol. 13, 537-550.
Aguiar, P.H., Borges dos Santos, R.R., Lima, C.A., Rios de Sousa, Gomes, H., Laranjeira, D.F., Santos, P.M., Barrouin-Melo, S.M., Conrado dos-Santos, W.L., Pontes-de-Carvalho, L., 2004a. Production of monoclonal antibodies against canine leukocytes. Hybrid. Hybridomics 23, 127-132.

Aguiar, P.H., Borges dos Santos, R.R., Laranjeira, D.F., Almeida dos Santos, M., Barrouin-Melo, S.M., Silva, T.M., Mengel, J.O., Conrado dos Santos, W.L., Pontes-de-Carvalho, L., 2004b. A novel monoclonal antibody against canine monocytes/macrophages. Hybrid. Hybridomics 23, 250-257.

Barrouin-Melo, S.M., Larangeira, D.F., Trigo, J., Aguiar, P.H.P., dos-Santos, W.L.C., Pontes-de-Carvalho, L., 2004. Comparison between splenic and lymph node aspirations as sampling methods for the parasitological detection of Leishmania chagasi infection in dogs. Mem. Inst. Oswaldo Cruz 99, 195197.

Barrouin-Melo, S.M., Laranjeira, D.F., Andrade-Filho, F.A., Trigo, J., Julião, F.S., Franke, C.R., Aguiar, P.H.P., dos-Santos, W.L.C., Pontes-de-Carvalho, L., 2006. Can spleen aspirations be safely used for parasitological diagnosis of canine visceral leishmaniosis? A study on asymptomatic and polysymptomatic animals. Vet. J. 171, 331-339.

Blavier, A., Keroack, S., Denerolle, P., Goy-Thollot, I., Chabanne, L., Cadore, J.L., Bourdoiseau, G., 2001. Atypical forms of canine leishmaniosis. Vet. J. 162, 108-120.

Christopher, M.M., 2003. Cytology of the spleen. Vet. Small Anim. 33, 135-152.

Cobbold, S., Metcalfe, S., 1994. Monoclonal antibodies that define canine homologues of human CD antigens: summary of the First International Canine Leukocyte Antigen Workshop (CLAW). Tissue Antigens, vol. 43. pp. 137-154.

Cotterell, S.E., Engwerda, C.R., Kaye, P.M., 2000. Enhanced hematopoietic activity accompanies parasite expansion in the spleen and bone marrow of mice infected with Leishmania donovani. Infect. Immun. 68, 1840-1848.

Deplazes, P., Smith, N.C., Arnold, P., Lutz, H., Eckert, J., 1995. Specific IgG1 and IgG2 antibody responses of dogs to Leishmania infantum and other parasites. Parasite Immunol. 17, 451458.

Engwerda, C.R., Ato, M., Cotterell, S.E., Mynott, T.L., Tschannerl, A., Gorak-Stolinska, P.M., Kaye, P.M., 2002. A role for tumor necrosis factor-alpha in remodeling the splenic marginal zone during Leishmania donovani infection. Am. J. Pathol. 161, 429437.

Faldyna, M., Sinkora, J., Knötigová, P., Levá, L., Toman, M., 2005. Lymphatic organ development in dogs: major lymphocyte subsets and activity. Vet. Immunol. Immunopathol. 104, 239-247.

Ferrer, L., Aisa, M.J., Roura, X., Portús, M., 1995. Serological diagnosis and treatment of canine leishmaniasis. Vet. Rec. 136, 514-516.

Gomes-Pereira, S., Rodrigues, O.R., Santos-Gomes, G.M., 2004 Dynamics of CD62L/CD45RB CD4+ and CD8+ lymphocyte subsets in hepatic and splenic tissues during murine visceral leishmaniasis. Immunol. Lett. 95, 63-70.

Guarga, J.L., Moreno, J., Lucientes, J., Gracia, M.J., Peribanez, M.A., Alvar, J., Castillo, J.A., 2000. Canine leishmaniasis transmission: higher infectivity amongst naturally infected dogs 
to sand flies is associated with lower proportions of $\mathrm{T}$ helper cells. Res. Vet. Sci. 69, 249-253.

Iniesta, L., Fernández-Barreto, S., Bulle, B., Gómez, M.T., Piarroux, R., Gállego, M., Alunda, J.M., Portús, M., 2002. Diagnostic techniques to detect cryptic leishmaniasis in dogs. Clin. Diagn. Lab. Immunol. 9, 1137-1141.

Kaye, P.M., Svensson, M., Ato, M., Maroof, A., Polley, R., Stager, S., Zubairi, S., Engwerda, C.R., 2004. The immunopathology of experimental visceral leishmaniosis. Immunol. Rev. 201, 239253.

Kontos, V.J., Koutinas, A.F., 1993. Old world canine leishmaniosis. Compendium on Continuing Education Small Animal 15, 949959.

Melby, P.C., Tabares, A., Restrepo, B.I., Cardona, A.E., McGuff, H.S., Teale, J.M., 2001. Leishmania donovani: evolution and architecture of the splenic cellular immune response related to control infection. Exp. Parasitol. 99, 15-25.

Molina, R., Lohse, J.M., Pulido, F., Laguna, F., Lopez-Velez, R., Alvar, J., 1999. Infection of sand flies by humans coinfected with Leishmania infantum and human immunodeficiency virus. Am. J. Trop. Med. Hyg. 60, 51-53.

Moreno, J., Nieto, J., Chamizo, C., González, F., Blanco, F., Barker, D.C., Alvar, J., 1999. The immune response and PBMC subsets in canine visceral leishmaniasis, before and after chemotherapy. Vet. Immunol. Immunopathol. 71, 181-195.

Natami, A., Sahibi, H., Lasri, S., Boudouma, M., Guessouss-Idrrissi, N., Rhalem, A., 2000. Serological, clinical and histopathological changes in naturally infected dogs with Leishmania infantum in the Khemisset Province, Morocco. Vet. Res. 31, 355-363.

Nieto, C.G., Garcia-Alonso, M., Requena, J.M., Miron, C., Soto, M., Alonso, C., Navarrete, I., 1999. Analysis of the humoral immune response against total and recombinant antigens of Leishmania infantum: correlation with disease progression in canine experimental leishmaniasis. Vet. Immunol. Immunopathol. 67, 117130.

Paranhos-Silva, M., Freitas, L.A.R., Santos, W.C., Grimaldi Jr., G., Pontes-De-Carvalho, L.C., Oliveira-Dos-Santos, A.J., 1996. A cross-sectional serodiagnostic survey of canine leishmaniasis due to Leishmania chagasi. Am. J. Trop. Med. Hyg. 51, 39-44.

Pinelli, E., Killick-Kendrick, R., Wagenaar, J., Bernardina, W., Real, G., Ruittenberg, J., 1994. Cellular and humoral immune responses in dogs experimentally and naturally infected with Leishmania infantum. Infect. Immun. 62, 229-235.

Quinnell, R.J., Courtenay, O., Garcez, L.M., Kaye, P.M., Shaw, M.A., Dye, C., Day, M.J., 2003. IgG subclass responses in a longitudinal study of canine visceral leishmaniasis. Vet. Immunol. Immunopathol. 91, 161-168.

Reis, A.B., Carneiro, C.M., Carvalho, M.G., Teixeira-Carvalho, A., Giunchetti, R.C., Mayrink, W., Genaro, O., Correa-Oliveira, R., Martins-Filho, O.A., 2005. Establishment of a microplate assay for flow cytometric assessment and it is use for the evaluation of age-related phenotypic changes in canine whole blood leukocytes. Vet. Immunol. Immunopathol. 103, 173-185.

Sanchez, M.A., Diaz, N.L., Zerpa, O., Negron, E., Convit, J., Tapia, F.J., 2004. Organ-specific immunity in canine visceral leishmaniasis: analysis of symptomatic and asymptomatic dogs naturally infected with Leishmania chagasi. Am. J. Trop. Med. Hyg. 70, 618-624.

Tafuri, W.L., De-Oliveira, M.R., Melo, M.N., Tafuri, W.L., 2001. Canine visceral leishmaniosis: a remarkable histopathological picture of one case reported from Brazil. Vet. Parasitol. 96, 203212.

Tipold, A., Moore, P., Jungi, T.W., Sager, H., Vandevelde, M., 1998. Lymphocyte subsets and CD45RA positive T-cells in normal canine cerebrospinal fluid. J. Neuroimmunol. 82, 90-95.

Varga, S.M., Welsh, R.M., 1996. The CD45RB-associated epitope defined by monoclonal antibody CZ-1 is an activation and memory marker for mouse CD4 T cells. Cell Immunol. 167, 56-62.

Williams, D.L., 1997. Studies of canine leukocyte antigens: a significant advance in canine immunology. Vet. J. 153, 31-39.

Zeppa, P., Picardi, M., Marino, G., Troncone, G., Fulciniti, F., Vetrani, A., Rotoli, B., Palombini, L., 2003. Fine-needle aspiration biopsy and flow cytometry immunophenotyping of lymphoid and myeloproliferative disorders of the spleen. Cancer 99 , 118-127.

Zuckermann, F.A., Peavey, C., Schnitzlein, W.M., Schabacker, D., Husmann, R.J., Yang, H., Saalmuller, A., Lunney, J.K., 1998. Definition of the specificity of monoclonal antibodies against porcine CD45 and CD45R: report from the CD45/CD45R and CD44 subgroup of the Second International Swine CD Workshop. Vet. Immunol. Immunopathol. 60, 367-387. 